\title{
INTEGRATED CONSERVATION STRATEGIES IN THE NETHERLANDS
}

\author{
SILVIA NALDINI ${ }^{1}$, ROB VAN HEES ${ }^{2}$ AND ERNST VAN DER GRIJP ${ }^{3}$ \\ ${ }^{1}$ Architectural Engineering + Technology \\ Delft University of Technology \\ e-mail: s.naldini@tudelft.nl \\ ${ }^{2}$ Architectural Engineering + Technology \\ Delft University of Technology \& R-Kwadraat MonumentenAdvies \\ e-mail: r.p.j.vanhees@tudelft.nl \\ ${ }^{3}$ Monumentenwacht Gelderland \\ e.vandergrijp@monumentenwacht-gld.nl
}

Keywords: Monumental Buildings, Visual Inspection, Quality in Restoration, Terminology

\begin{abstract}
In the Netherlands a program for the enhancement of quality in the restoration of monumental buildings is presently carried out, stimulated by national authorities and coordinated by the foundation ERM. Guidelines are issued by the branches involved, from architects to masons, under guidance of an experts' committee, to perform interventions on monuments and assess them. The aim of this paper is to discuss the contributions to the program offered by different actors active in the field of conservation, the existing synergies and the potential of using a common language and approach. These are needed to facilitate communication and exchange knowledge. The use of the terminology of MDCS (Monument Diagnosis and Conservation System) can help create a community of stakeholders. Sharing the damage terminology and methodology can help achieving a clear and systematic assessment of damage and its causes. It can further improve the communication among all stakeholders, including owners and laymen, stimulating cooperation, and can allow monitoring of damage and interventions.
\end{abstract}

\section{INTRODUCTION}

In the Netherlands, a program for ensuring Quality in Restoration, stimulated by national authorities, is presently carried out. Its focus lies on the development of guidelines by the various branches, such as contractors, architects and masons, involved in conservation and restoration of monuments. The use of both terms 'restoration' and 'conservation' in the description of the program, are meant to indicate different levels of the interventions. The aim of this paper is to discuss the contributions to the program of different actors active in the field and the existing synergies. In particular attention is focussed on the present role of the system MDCS (Monument Diagnosis and Conservation System) and its potential for facilitating communication and exchange of knowledge [1]. Having clarified the tasks of important actors involved in the conservation of Dutch monuments and their aims, an overview of the situation 
in the Netherlands is drawn. Strong points and difficulties are discussed in the strategies for this far-reaching program for the enhancement of the quality of monument conservation in the country.

\section{QUALITY IN RESTORATION IN THE NETHERLANDS}

Already in the 1970's it became evident that after the restoration of a monumental building, preventive conservation and maintenance were needed. The Monumentenwacht organisation was created - at a provincial level - to carry out regularly inspections, to assess the state of conservation and also to perform minor interventions [2]. The commitment of the organisation concerns Dutch monumental buildings. In the last decades the assistance of Monumentenwacht (MW) in deciding on necessary maintenance activities, has become essential for private owners and for administrators of non-iconic buildings in general. In these cases the decision on the conservation plan is in fact mainly entrusted to the MW inspectors, whereas, in the case of iconic buildings, a restoration team is usually formed including an architect, experts from the Dutch Cultural Heritage Agency (RCE), contractors and often MW inspectors [3]. Subscription to the Monumentenwacht organisation is not mandatory.

Monumentenwacht plays an important role in assessing the work done by contractors, hence contributing to achieve the expected quality in the conservation and maintenance interventions on historic structures. The valuation of the interventions is based on the assessment of the technical and historical compatibility of the work done, in terms of respect for of the historic (original) materials an

Both inspectors and co that professionalism as already discussed Creating or enhancing that time the policy on the
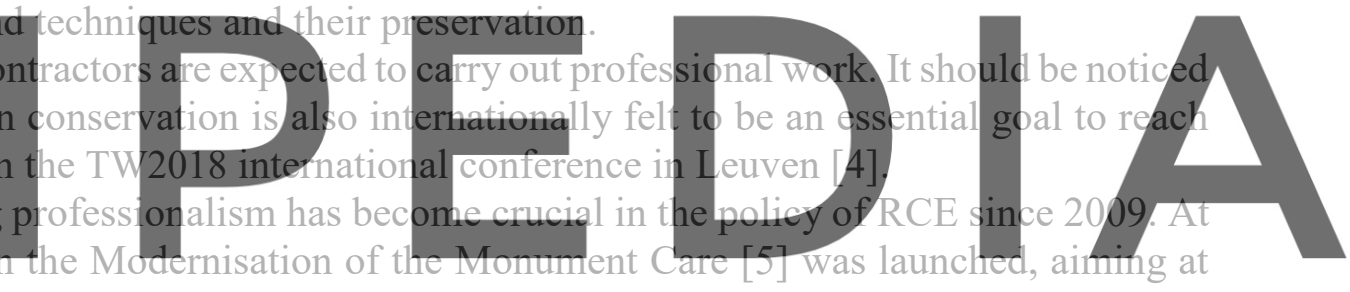

the enhancement of the technical quality in restoration and of the ethical approach. These

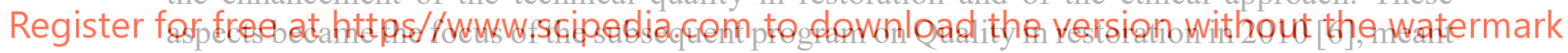

to achieve a controllable quality level in restoration of heritage buildings and sites. The program was founded on self-regulation. The Dutch foundation for a recognized restoration standard in the preservation and restoration of monumental buildings and sites, the foundation ERM [6] was created, to co-ordinate the actions of the branches involved in conservation, ranging from the architects and contractors to the masons and the carpenters.

Each of these branches has developed its own guidelines to meet defined quality standards. A committee of experts, created by the foundation ERM, has been appointed to assist and guide this bottom-up initiative. The foundation ERM has also the task of disseminating the execution guidelines, making them accessible online to all interested parties. Further, ERM provides the means for obtaining a certification for the execution of the work and superintends the controls on the work done. It is interesting to notice that any actor in conservation - even those not possessing a certification - can stipulate to perform an intervention in accordance with the execution guidelines.

The ERM guidelines for carrying out visual inspections of monuments [7] are based i.a. on the handbook of Monumentenwacht and the NEN standards [8,9]. Also other provincial quality regulations refer to the ERM guidelines. 
Concerning the already issued ERM guidelines, it was observed that the used terminology for indicating the damage found was not always univocal and clear and it was decided that all guidelines needed to refer to one terminology only, to avoid misunderstandings. The terminology included in the MDCS system (see further) was selected to be used as a reference for the guidelines. The system and the atlases can be found on the online platform MonumentenKennis [1] on Monuments (and) knowledge, created by TNO (the Netherlands Organization for Applied Scientific Research), RCE and the faculty of Architecture of TU Delft (Delft University of Technology) [10]. This broad co-operation aims at providing scientific knowledge concerning monuments to all people involved in conservation. The dissemination of the knowledge to non-specialists, including monument owners, is entrusted to Monumentenwacht and other actors in conservation working for owners and laymenadministrators of the monuments [figure 1].

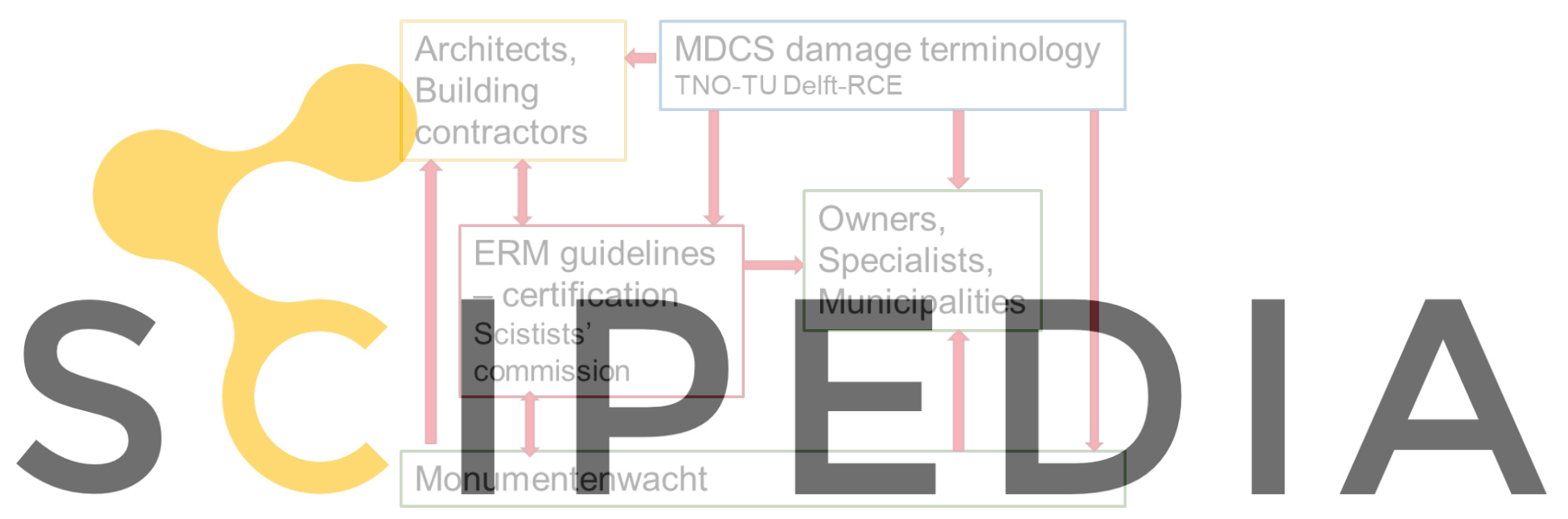

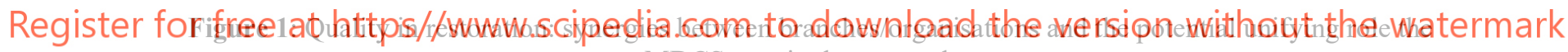
MDCS-terminology can play

\subsection{MDCS: identification of damage types for diagnosis and intervention}

Already in the 1990's the need was felt for methods to achieve a homogenous approach in conservation. The cooperation of experts from Belgium, the Netherlands, Italy and Germany in the MDDS (Masonry Damage Diagnostic System) project [11] resulted in the development of a system able to guide the user in the subsequent phases of the work, from the visual inspection of historic brick masonry to the diagnosis of the damage found. The part developed for identifying the masonry materials and the damage assessed, became the starting point for the further development to other stone-like materials (such as stone, mortars, plasters, concrete) and even structural damages and proved to be an important means for communication The stand-alone MDDS was further used in national and international projects and became ultimately the web-based 'MDCS'. In a 'wiki' section, additional information can be found and relevant diagnostic and intervention techniques, all presented in a way meant for practical use. On the basis of a sound diagnosis of the causes of damages a plan can be made for a suitable, durable and ethically correct intervention. 
The theoretical scientific knowledge made accessible through the MonumentenKennis platform and the MDCS wiki, can be retrieved by all stakeholders, which is in line with the intention of the ERM guidelines. Monumentenwacht and other actors in contact with the owners and the users of building can convey the knowledge to laymen. In order to put the theory into practice, following a methodology is deemed necessary, to clarify the various phases of the conservation process, from the visual inspection and the identification of the materials and the damage found, to the hypotheses on the damage mechanism(s), the control of the hypotheses and the diagnosis (as basis for the intervention).

\subsection{Visual inspections}

For the visual inspection, MDCS includes atlases for the identification of the materials used in monuments and the damage observed. Each term is unique and furnished with illustrations and a definition. Next to a structural damage atlas with crack patterns and deformations, the atlases concern different masonry materials (e.g. stone, brick, mortar and plaster) as well as historic concrete. The module on historic concrete will benefit from the outcomes of the ongoing international project CONSECH20 [12]. Modules on timber, glass and artificial materials and the forms of deterioration they may show will be added in the future.

Operating in line with the system is leading to the formation of a community of users, talking the same language and using the same approach: damage identification $\rightarrow$ hypotheses on the causes of damage $\rightarrow$ control of hypotheses (testing/expert's opinion) $\rightarrow$ diagnosis $\rightarrow$ intervention. The use of a common terminology is necessary and makes it possible to
understand reports and perform monitoring of the developinent of the damage. A precipe
identification of damage and analysis of its cause further lead to consistent interventions: their
effectiveness can also be monitored and reported within MDCS.
Conservation practice shows that there is often no agreement with respect to the meaning of a
term, or that a damage type is given different names (and interpretations) by different actors.

An example is the difference between salt efflorescence and encrustation. Both are clearly

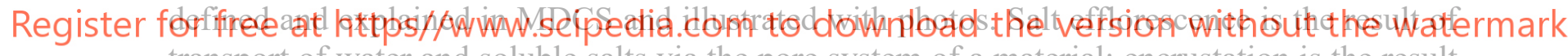
transport of water and soluble salts via the pore system of a material; encrustation is the result of a process of percolation of water through voids and cracks, in combination with leaching of mortar constituents such as lime, which is subsequently deposited at the surface [figure 2]. A most important consequence of using a univocal damage terminology, is that this allows a clear distinction of phases, the first being that of the identification based on visual assessment and the second being the development of hypotheses on the causes of damage under the given circumstances. When the causes of damage are unclear, this phase ends with an indication of the tests/measurements needed to control the hypotheses and explain the damage. 

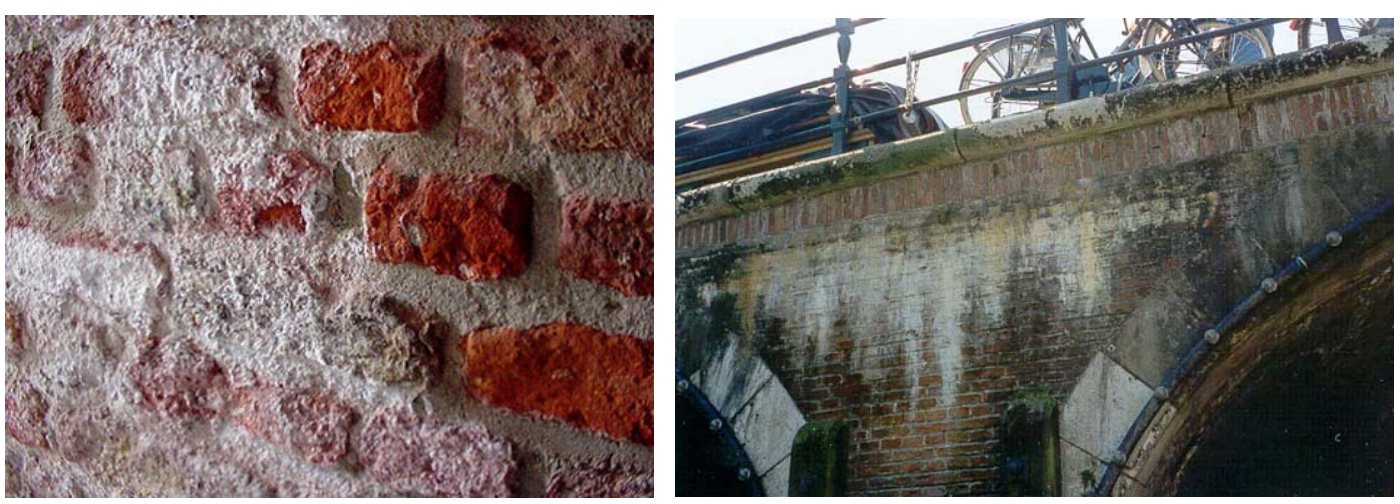

Figure 2: Salt efflorescence (1) and encrustation due to leaching of mortar constituents (r)

\subsection{The potential of Monumentenwacht}

The creation of the Monumentenwacht organization in the 1970's marked the moment when the conservation of the built heritage in the Netherlands started to be organized in terms of prevention and to include large numbers of objects. Active at a provincial level, the inspectors of Monumentenwacht perform regular surveys on the state of conservation of monuments and support their owners in maintaining them. According to the Dutch Heritage Legislation [13],

the owners are in fact expected to maintain their monumental buildings,

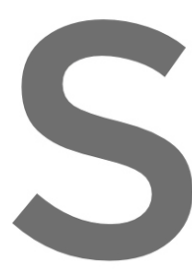
The strong points of the of the organisation in operating based on pron conservation-restoration annual) inspections per
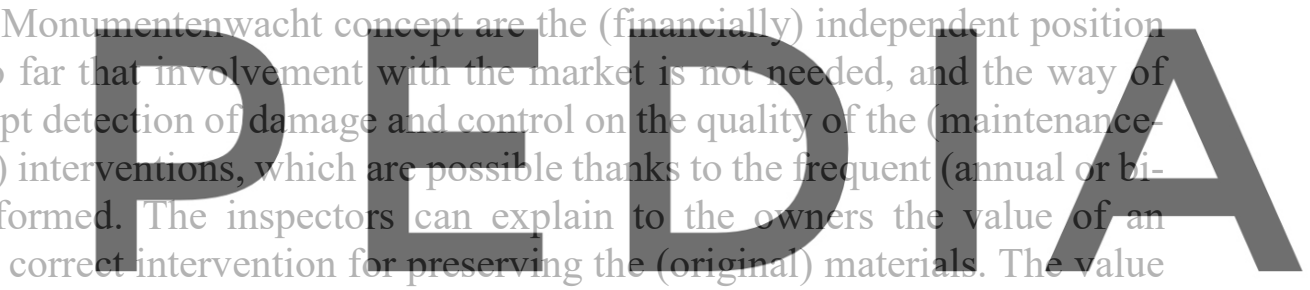
of the activities of MW in terms of preventive conservation has been discussed elsewhere [2,

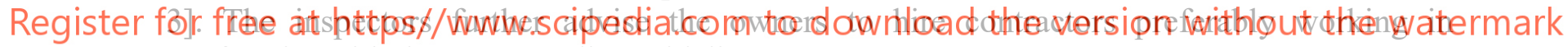
conformity with the ERM quality guidelines.

\section{4 'Monumentenwacht moves'}

Because of the growing relevance of the inspectors' advisory task for the owners of a broad range of non-iconic buildings, the project 'Monumentenwacht moves' was started in cooperation with the faculty of Architecture of the TU Delft. This project aims at empowering the inspectors to achieve better structured and deeper analyses of the damage. This means providing them with up to date knowledge, derived from scientific research, and with a better methodology for their investigations. The program involves the Monumentenwacht organisations of the provinces of Gelderland, North Brabant and Limburg and is intended to be spread to the other provinces in future.

In workshops TU Delft organizes for Monumentenwacht, MW-inspectors are made acquainted with the MDCS terminology for visually identifying damage phenomena. Using the MDCS damage atlas as a basis, hypotheses are made on possible causes of damage, according to the method included in the MDCS system. It is of crucial importance that the possibilities, but also the limitations of a visual inspection are clear to the inspectors and consequently to the members 
(owners). In the current Monumentenwacht reports definitive conclusions on the causes of damage are often presented (diagnosis), which are in fact mere hypotheses based on the visual inspection and on personal experience.

Instead, the (correct) identification of the visible damage types and the formulation of hypotheses explaining their occurrence need to be clearly separated. The first step, the identification of the damage found, referring to a standardized system, will have an objective character. The formulation of hypotheses needs to be supported by argumentation (e.g. circumstances, information on history and former interventions). This logical line, developed in the MDCS methodology, makes it possible to decide if/when the advice of experts or laboratory and further investigations are needed (based on sampling, measuring,...) to evaluate the hypotheses and come to a diagnosis.

The use of the common terminology makes scientific communication possible as well as the comparison between yearly inspection reports. Comparison/monitoring can show the development of not treated damage, but also the effects of interventions on materials and structure.

A passage of a MW report made before the adoption of the new terminology has been selected to show a description of damaged pointing. No reference to the source is given for privacy reasons. The description of the type of damage rises questions: 'especially in the higher part (of the masonry) the pointing is damaged, cracked, has lost adhesion, is detached or washed out'. It is clear for the reader that the pointing is damaged and gone, but in which way? In one piece

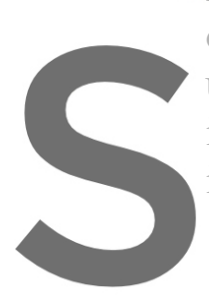
or through e.g. erosion? It is fundamental to
understand the mechanism behind it: for examp
its cohesion and is indeed pushed by e.g. the fo
in the case of erosion the pointing loses particl
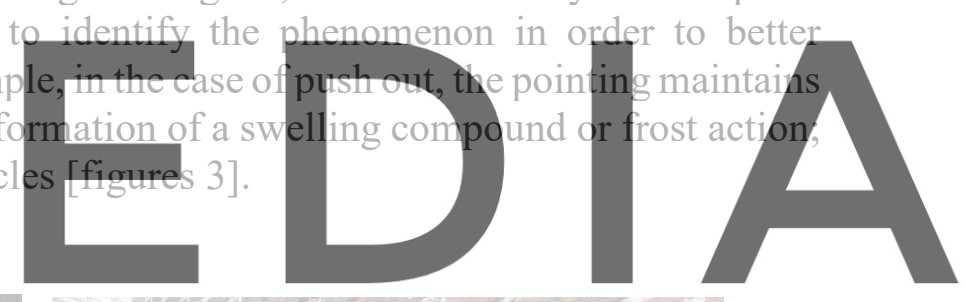

Register for free at https//www.scipedia.com to download the version without the watermark
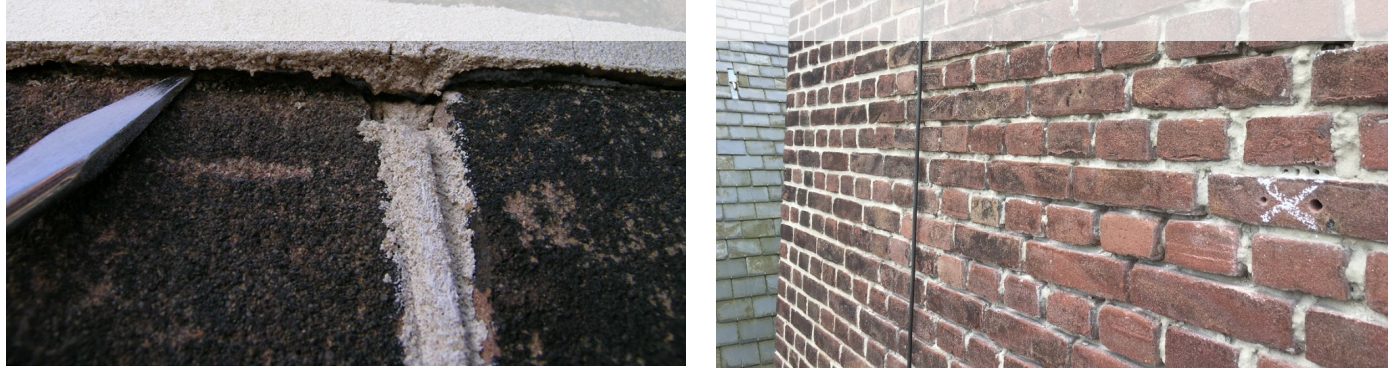

Figure 3 Examples of push out of pointing(l) and erosion (r)

The passage of a MW report made before the course concerning a certain location in a building is compared to the passage on the same location based on the MDCS methodology [figures 4, 5]. 


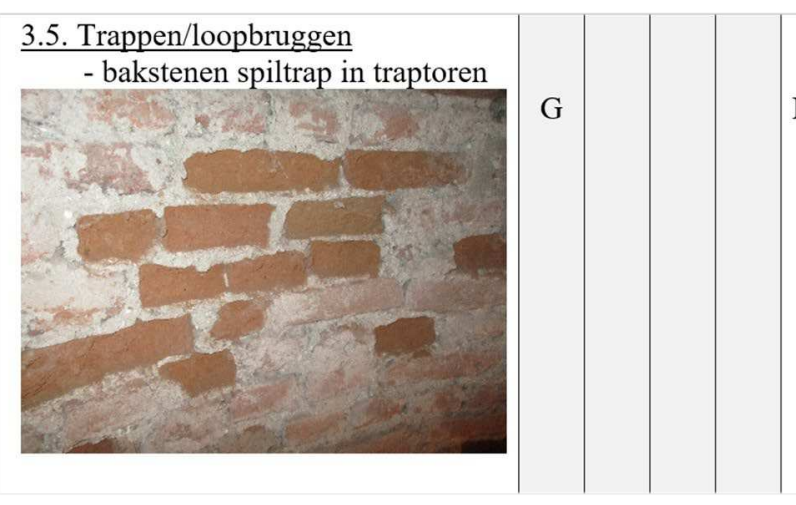

Behoudens enige vochtdoorslag en verpulverde stenen.

Figure 4: Passage of a MW report. The masonry is in a good state $(\mathrm{G})$, with the exception of some moisture penetration and powdering of the stones. (No reference to the source is given for privacy reasons).

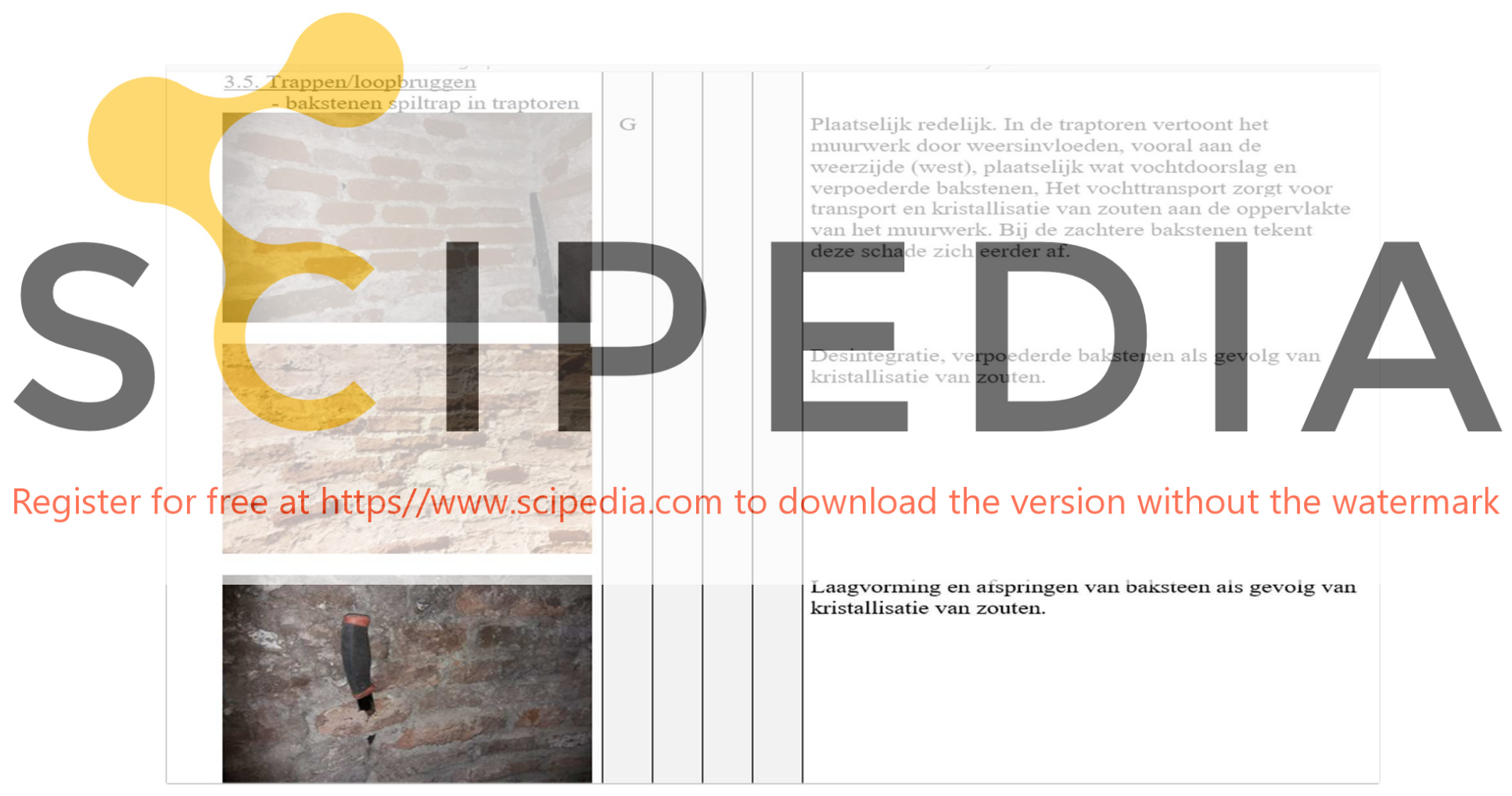

Figure 5: Passage of a MW report concerning the same masonry as in fig. 4, but written on the basis of the MDCS terminology and methodology. The damage is better identified and the damage mechanism explained. (No reference to the source is given for privacy reasons).

In the first example the state of conservation of the masonry of a staircase is described as 'good', with the exception of some moisture penetration and powdering of the bricks. In the following report, MDCS terminology and methodology presented in the course (Monumentenwacht moves) are implemented. The identification of damage and its context is more complete and clear. Although the general state of conservation is rated as good, locally 
occurring damage is reported at the west side. The damage is identified as powdering, and moisture penetration is assessed. The mechanism is also explained: due to the moisture penetrated in the wall (soluble) salt is transported and deposited at the surface of the masonry, where it crystallizes causing damage to the 'softer' bricks in the first place. The specific damage found at different locations is disintegration $\rightarrow$ powdering (second picture) or layering and spalling (third picture). This way of reporting and explaining damage - based on visual assessment, which is inherent to the way of operating of MW - provides the inspector with a basis for planning further investigations (e.g. moisture and salt distribution) or else monitoring the extension and severity of the damage. MW Gelderland is presently developing a tool facilitating the storage of the information on the damage types and interventions. Such a tool would be easy to manage and could be used during (MW) inspections; it is deemed important for recording data, which are presently not always traceable, i.e. data concerning interventions.

\subsection{The Quality in Restoration program}

The Quality in Restoration program includes theoretical, ethical and technical parts which should to be referred to for carrying out suitable interventions on monuments. The main aim is to encourage the actors involved in the conservation of monumental buildings to develop a correct, professional attitude. The need for a professional recognition was at first felt by the restoration contractors, who started the process.

ERM guidelines have been by now produced by numerous branches active in conservation: in the guidelines, since short, links are made to the MiDCS (damage) terminology attases. In the case of privately-owned technique and material with the guidelines. A co-operation TU Delft - ERM on the revisionats points lie. Also in the gutidelines, like in the rep
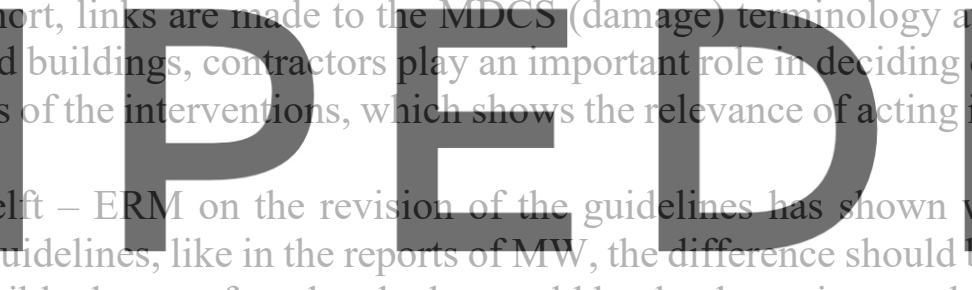

between what is the visible damage found and what could be the damaging mechanism having

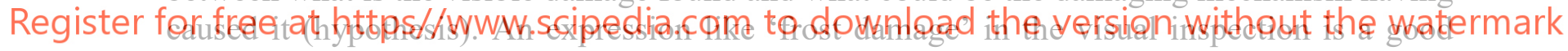
example of an incorrect formulation, where the supposed origin of the damage is used to qualify the type, which is in fact not described. This points at the need of carefully distinguishing the visual form of deterioration (e.g. crumbling, exfoliation) from its (hypothetical) cause (frost action).

\section{CO-OPERATION ON DIFFERENT LEVELS: COMMON LANGUAGE}

The connection that exists between the knowledge platform MonumentenKennis, the ERM Quality in restoration program and the activities of Monumentenwacht reflects the involvement of different actors in the development of conservation strategies at a national level and shows the possibilities of synergies. When this 'system' becomes fully operational, the technical knowledge deriving from the academic world and from scientific research will find its way towards dissemination and use in practice; the quality guidelines created by the branches and related to existing (national and international) standards are meant to create the means for different actors to have the quality of their work recognized.

In order to enhance the use of the common terminology, a damage overview fan deck on damage to stone-like materials has been developed and will be spread by the ERM foundation. 
Following the fan deck a MDCS app for smartphones will be developed.

\subsection{Sharing knowledge}

In a recent $\mathrm{PhD}$ research on the improvement of the Quality of conservation interventions, the co-operation among stakeholders based on knowledge sharing is valued as an essential means [14]. The expertise of various people involved in conservation can be thus used to construct a sound basis for the interventions: the relevance of this approach has been addressed as a shared value of the MW organizations of Gelderland, Limburg and North Brabant in a study on methods of operation in practice [15].

The need for sharing knowledge is felt at various levels. A conference with round table sessions was recently organized by the Dutch National Monuments Organization for monument managers of monumental buildings for discussing future ways of co-operating with government on conservation [16]. It was interesting to notice that owners expressed the need of easily finding in a shared website the necessary information to orient, in case of occurrence of damage to the monumental buildings they manage. They pleaded for the creation of a sort of platform where they could share theoretical and practical information. The problem with such an action, wanted by laymen and directed to them, is that the possibility of referring to cases of damage assessment and interventions in a constructive and useful way lies in the completeness of reports, which is often not clear to non-experts. In order to extract useful information from a

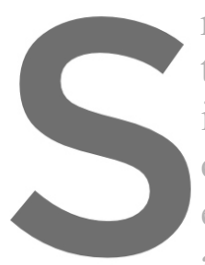
report this needs to

transformation in the intervention. Only when t

conservation process an extrapolated to help approach lie at the basis of a st
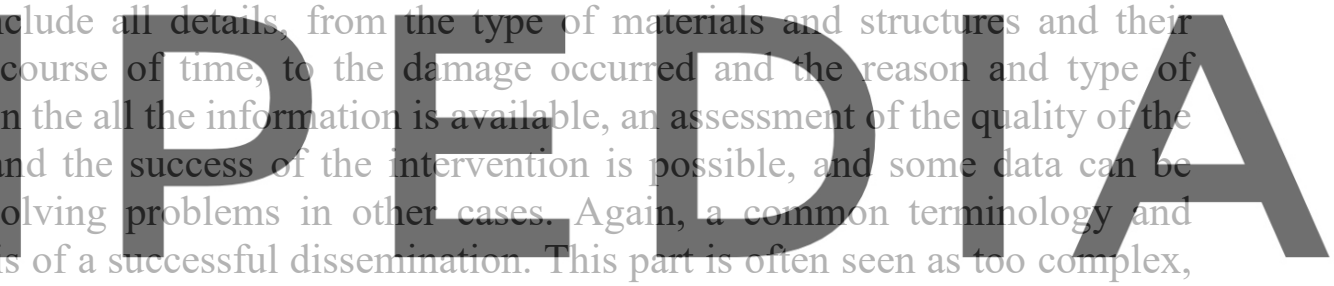

and yet it is essential. The question arises as to whether and how laymen can profit from the

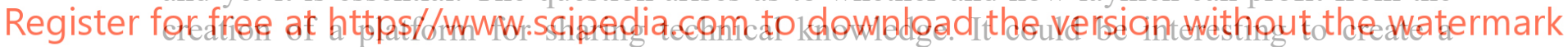

community of monument managers, instructed on the values of historic materials and techniques and the needs for their preservation in terms of quality. They could be advised on how to proceed, from the choice of certified inspectors and contractors, to the need of claiming reports including all the steps taken and allowing the assessment of the intervention. In fact Monumentenwacht already gives courses to layman owners on specific subjects. Yet these are their own members, and more (professional) owners should be reached likewise.

\subsection{Involvement of owners and users}

Owners play a relevant role in the conservation of monumental buildings in the Netherlands [17]. Owners and users of buildings should be encouraged to participate in maintenance and conservation activities. A methodology for involving different stakeholders in conservation practices and maintenance, at different levels, from signalling damage to actually intervening, has been carried out in Portugal. Positive results were obtained in various case studies on intangible and tangible levels: from increased awareness of the relevance of the monumental buildings dealt with, to direct involvement of communities in conservation practices $[18,19]$.

Empowering laymen stakeholders like owners and users to recognize and signal damage 
could be profitable for different reasons: in the first place it would form the basis for starting maintenance activities, and further it can stimulate the emotional attachment of owners and users to their buildings.

\section{CONCLUSIONS}

In the Netherlands a program on the enhancement of quality in the restoration/conservation of monumental buildings has been promoted by the RCE and coordinated by the foundation ERM. The program has resulted in the creation of guidelines by the involved branches both for obtaining a certification and for performing adequate interventions on monuments. The program is meant to reach all the stakeholders in conservation, from the architects to the masons and the owners and users. The theoretical knowledge provided by various experts should be conveyed to the actors working in practice by MW and other actors. The synergies between the program and the work of different institutions active in the field of conservation can be made stronger through the use of the damage terminology and approach of MDCS, which is a strong tool that can substantially contribute to restoration quality. A clear and univocal identification of the damage, based on a visual assessment, has shown to be a good basis not only for communication and monitoring but also for making well-supported hypotheses on the cause(s) of the damage. Important is the distinction and clarification of the steps leading to the diagnosis. Employing this systematic procedure is expected to contribute to conservation quality and facilitate the creation of a community, where theoretical scientific knowledge can be exchanged

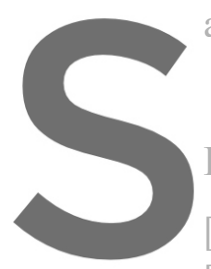
and conveyed to practict
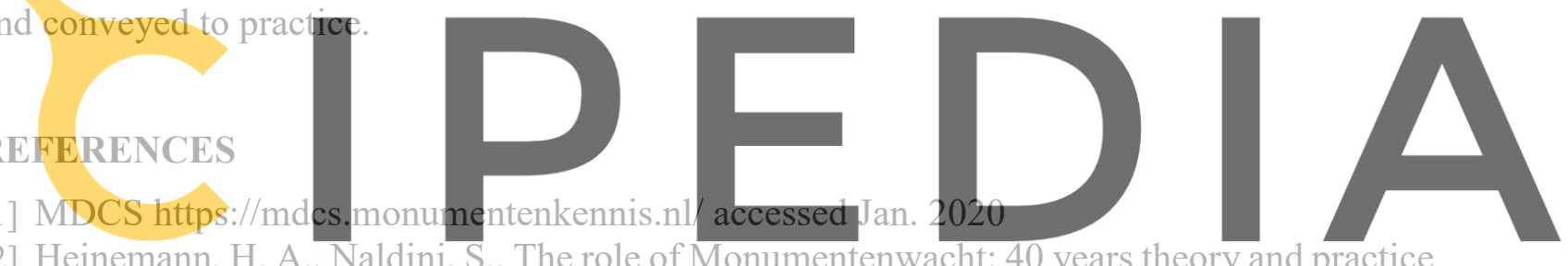

[2] Heinemann, H. A., Naldini, S., The role of Monumentenwacht: 40 years theory and practice

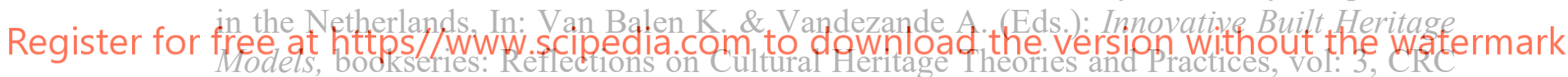

Press / Balkema, Taylor\&Francis Group (2018), pp. 107-116

[3] Naldini, S., Heinemann H. A., Hees, R.P.J. van 2018, Monumentenwacht and Preventive Conservation: Changes, In: Van Balen K. \& Vandezande A. (Eds.): Innovative Built Heritage Models, bookseries: Reflections on Cultural Heritage Theories and Practices, vol: 3, CRC Press / Balkema, Taylor\&Francis Group (2018), pp. 117-124

[4] Naldini S., Hunen van M., Guidelines for quality of interventions in built Cultural Heritage, In: Van Balen K., Vandesande A. (Eds.), Professionalism in the Built Heritage Sector, bookseries: Reflections on Cultural Heritage Theories and Practices, vol: 4, CRC Press / Balkema, Taylor \& Francis group (2019), pp. 87-93

[5] MOMO, Modernisering Monumentenzorg, https://www.parlementairemonitor.nl/9353000/1/j9vvij5epmj1ey0/vi8y8gd6tkzm, accessed Jan. 2020

[6] ERM http://www.stichtingerm.nl/, accessed Jan. 2020

[7] https://www.stichtingerm.nl/richtlijnen/url2005, accessed Jan. 2020

[8] https://www.stichtingerm.nl/onderhoud-en-restauratie/periodieke-inspecties-van-uwmonument Handboek Monumentenwacht Gelderland, accessed Jan. 2020 
[9] NEN 2767 Condition assessment of building and installation components - Part 2: Lists of faults

[10] https://www.monumentenkennis.nl/, accessed Jan. 2020

[11] Franke L., Schumann I., Hees R.P.J. van, Klugt L.J.A.R. van der, Naldini S., Binda L., Baronio G., Balen K.E.P. Van, Mateus J., Damage Atlas. Classification of Damage Patterns found in Brick Masonry, Research Report No 8, Vol. 2, European Commission, (1998), Fraunhofer IRB Verlag, ISBN 3-8167-4702-7

[12] https://consech20.eu/, accessed Jan. 2020

[13] Heritage legislation (Erfgoedwet) 2017, https://wetten.overheid.nl/BWBR0037521/201709-01, accessed Jan. 2020

[14] Roy Van N., Quality Improvement of Repair Interventions on Built Heritage, $\mathrm{PhD}$ thesis KU Leuven (2018)

[15] Naldini S., Varst de G., Koning de S., Grijp van de E., Quality of restoration of monuments: the role of Monumentenwacht, In: Van Balen K., Vandesande A. (Eds.), Preventive Conservation, bookseries: Reflections on Cultural Heritage Theories and Practices, CRC Press / Balkema, Taylor \& Francis group (in press),

[16] https://erfgoedstem.nl/wp-content/uploads/2019/01/Uitnodiging-NMo-NU-12-Overheiden-professionele-erfgoedeigenaren.pdf

[17] Kleuver, J. De, Horst, A. Van Der, Özgül, P., Evaluatie stelsel kwaliteitsborging en Stichting ERM, DSP groep - rapport (2017),

https://www.rijksoverheid.nl/documenten/rapporten/2017/01/01/evaluatie-stelselkwaliteitsborging-en-stichting-erm

[18] Ferreira, T.C, Contributions for the implementation of preventive conservation and maintenance strategies in the Faculty of Architecture of the University of Porto, In: Amoêda, R., Lira, S. and Pinheiro, C. (Eds), Proceedings 3rd International Conference on Preservation, Maintenance and Rehabilitation of Historical Buildings and Structures, REHAB, Braga (2017), pp. 255-264.

[19] Ferreira T. C., Bridging planned conservation and community empowerment: Portuguese case studies, Journal of Cultural Heritage Management and Sustainable Development (2018): //doi.org/10.1108/JCHMSD-05-2017-0029e 